\title{
A tribo Dalbergieae (Leguminosae - Papilionoideae) em um trecho de Floresta Estacional Semidecidual das Terras Baixas, João Pessoa, Estado da Paraíba, Brasil
}

\author{
- Damara Alves Mendonça ${ }^{1}$, Pedro da Costa Gadelha Neto ${ }^{2}$, $D$ Ana Paula Fortuna Perez ${ }^{3}$, \\ - Ana Paula Souza Caetano ${ }^{4}$ e $\odot \underline{R u b e n s ~ T e i x e i r a ~ d e ~ Q u e i r o z ~}^{1,5}$
}

Recebido: 29 junho 2018; aceito: 14 maio 2019

Como citar: Mendonça, S.A., Gadelha Neto, P.C., Perez, A.P.F., Caetano, A.P.S. \& Queiroz, R.T. 2019. A tribo Dalbergieae (Leguminosae - Papilionoideae) em um trecho de Floresta Estacional Semidecidual das Terras Baixas, João Pessoa, Estado da Paraíba, Brasil. Hoehnea 46: e622018. http://dx.doi.org/10.1590/2236-8906-62/2018.

ABSTRACT - (The Dalbergieae tribe (Leguminosae-Papilionoideae) in a Lowland Seasonal Semideciduous Forest stretch, João Pessoa, Paraíba State, Brazil). This work presents a taxonomic study of species of Leguminosae - Dalbergieae from Mata do Buraquinho, João Pessoa, Paraíba State, which is a mixed area composed by elements of Rain Forest, the Amazonian flora, and the Bahian Hileia. The study was based on field collections and morphological analysis of herbarium specimens. As a result, 11 native species distributed into seven genera were found: Aeschynomene evenia, A. viscidula, Andira legalis, A. nitida, Arachis pintoi, Machaerium hirtum, Pterocarpus rohrii, Stylosanthes capitata, S. guianensis, S. viscosa, and Zornia latifolia. Of these species, six are bushes, four are trees, and one is an herb. The occurrence of Aeschynomene evenia, Andira legalis, Arachis pintoi, and Stylosanthes gracilis is recorded for the first time in the state of Paraíba. Identification key, descriptions, comments on the morphology and illustrations for the species are presented.

Keywords: Atlantic Rainforest, Fabaceae, floristic diversity, plant taxonomy

RESUMO - (A tribo Dalbergieae (Leguminosae - Papilionoideae) em um trecho de Floresta Estacional Semidecidual das Terras Baixas, João Pessoa, Estado da Paraíba, Brasil). Este trabalho apresenta um estudo taxonômico das espécies de Leguminosae - Dalbergieae para a Mata do Buraquinho, João Pessoa, Paraíba, uma área mista contendo elementos de Mata Atlântica, da flora amazônica e da Hileia Baiana. O trabalho tem por base coletas de campo e a análise morfológica de materiais depositados em herbários. Foram encontradas 11 espécies nativas distribuídas em sete gêneros: Aeschynomene evenia, A. viscidula, Andira legalis, A. nitida, Arachis pintoi, Machaerium hirtum, Pterocarpus rohrii, Stylosanthes capitata, S. guianensis, S. viscosa e Zornia latifolia. Desse total de espécies, seis com hábito subarbustivo, quatro com hábito arbóreo e uma herbácea. A ocorrência de Aeschynomene evenia, Andira legalis, Arachis pintoi e Stylosanthes gracilis é registrada pela primeira vez para o Estado da Paraíba. São apresentados chave de identificação, descrições, comentários sobre a morfologia e ilustrações para as espécies.

Palavras-chave: diversidade florística, Fabaceae, taxonomia vegetal

\section{Introdução}

Leguminosae Juss. com aproximadamente 751 gêneros e cerca de 19.500 espécies (LPWG 2013) é a terceira maior família de angiospermas (Mabberley
2008). Diversos estudos reconhecem o monofiletismo da família (Polhill 1994, Doyle et al. 1997, Lewis \& Schrire 2003, LPWG 2013), entretanto, a classificação das subfamílias foi recentemente alterada (LPWG 2017). A tradicional divisão em três subfamílias,

1. Universidade Federal da Paraíba, Departamento de Sistemática e Ecologia, Campus I, Lot. Cidade Universitária, 58051-900 João Pessoa, PB, Brasil

2. Universidade Federal da Paraíba, Campus II, Rodovia 079 Km 12, 58397-000 Areia, PB, Brasil

3. Universidade Estadual Paulista, Programa de Pós-Graduação em Ciências Biológicas (Botânica), Instituto de Biociências, Departamento de Botânica, Rua Prof. Dr. Antônio Celso Wagner Zanin, 250, Distrito de Rubião Junior, 18618-689 Botucatu, SP, Brasil

4. Universidade Federal de Mato Grosso, Instituto de Biociências, Departamento de Botânica e Ecologia, Avenida Fernando Corrêa da Costa 2367, 78060-900, Cuiabá, MT, Brasil

5. Autor para correspondência: rbotanico@gmail.com 
Caesalpinioideae, Mimosoideae e Papilionoideae (Faboideae), foi substituída por uma nova proposta baseada em estudos taxonômicos e moleculares realizada pelo Legume Phylogeny Working Group (LPWG 2017), que reconhece seis subfamílias, sendo elas: Caesalpinioideae DC. emend. LPWG; Cercidoideae LPWG; Detarioideae Burmeist.; Dialioideae LPWG; Duparquetioideae LPWG e Papilionoideae DC.

Dentre as subfamílias atualmente reconhecidas, Papilionoideae destaca-se por incluir cerca de dois terços de todos os gêneros e espécies da família (Polhill 1994, LPWG 2017), ocorrendo em diferentes formações vegetais, desde as zonas tropicais e subtropicais até as zonas temperadas de todo o mundo (Polhill 1981, Lewis et al. 2005). A diversidade desta subfamília está representada por aproximadamente 503 gêneros e cerca de 14.000 espécies, distribuídas em 28 tribos (LPWG 2017).

Dalbergieae é uma das maiores tribos de Papilionoideae, apresentando 46 gêneros e cerca de 1.367 espécies com distribuição principalmente pantropical (Cardoso et al. 2013). Quanto à classificação, esta tribo vem passando por variadas modificações, principalmente após avanços nos estudos de filogenia molecular (Doyle et al. 1997, Lavin et al. 2001, Pennington et al. 2001). Atualmente, a tribo inclui grande parte dos representantes da antiga tribo Dalbergieae, com exceção de Andira Lam., Hymenolobium Benth., Vatairea Aubl. e Vataireopsis Ducke, todos os gêneros das antigas tribos Aeschynomeneae e Adesmieae, os gênero Acosmium Schott, Maraniona C.E. Hughes, G.P. Lewis, Daza \& Reynel e Steinbachiella Harms, além de representantes da subtribo Bryinae, tribo Desmodieae (Lavin et al. 2001, Pennington et al. 2001, Cardoso et al. 2012a,b, 2013, Hughes et al. 2004, Lewis et al. 2012, LPWG 2013).

Leguminosae constitui uma das famílias mais diversas na Mata Atlântica do Brasil, com cerca de 964 espécies, sendo superada apenas por Orchidaceae (BFG 2015). O domínio Atlântico destaca-se entre os domínios fitogeográficos por apresentar a maior riqueza de espécies de Angiospermas no país (BFG 2015). Entretanto, no nordeste, estes estudos florísticos com Leguminosae são escassos, e foram realizados apenas na Paraíba (Dionísio et al. 2010) e no Rio Grande do Norte (Queiroz \& Loiola 2009, São-Mateus et al. 2013).

Neste contexto, o presente trabalho teve por objetivo contribuir com o conhecimento da diversidade de Leguminosae, mais especificamente, da tribo Dalbergieae, em uma área de Mata Atlântica no nordeste brasileiro. Para tal foram realizados o levantamento florístico e o estudo taxonômico das espécies desta tribo em uma região de Floresta Estacional Semidecidual das Terras Baixas no Estado da Paraíba, incluindo a elaboração de descrições e ilustrações e uma chave para a identificação dos táxons confirmados.

\section{Material e métodos}

O local de estudo, conhecido como Mata do Buraquinho, está situado no município de João Pessoa, Paraíba, e localizado a sudeste do centro urbano nas coordenadas $7^{\circ} 6^{\prime} 17^{\prime \prime} \mathrm{S}, 34^{\circ} 52^{\prime} 42^{\prime \prime} \mathrm{O}$ (figura 1), no litoral do Estado, a uma altitude média de $45 \mathrm{~m}$, na formação geológica do Baixo Planalto Costeiro, abrangendo uma área total de 471 ha (Barbosa 1996). O clima na região é quente e úmido, com temperaturas médias anuais oscilando entre 24 e $27^{\circ} \mathrm{C}$, com pluviosidade de 900 a $1.800 \mathrm{~mm} /$ ano e umidade relativa em torno de $80 \%$ (Lima \& Heckendorff 1985). O solo é predominantemente pobre e arenoso, constituído por sedimentos areno-argilosos, pouco consolidados do grupo Barreiras. Em alguns locais, chegam a se formar verdadeiros bolsões de areia que apresenta uma vegetação fisionomicamente diferente, conhecida como Tabuleiro (Barbosa 1996). A vegetação constitui um legítimo representante das matas pluviais costeiras nordestino-brasileiras, verificando-se em sua composição a presença de espécies não só da Mata Atlântica como também da flora amazônica e da hileia baiana (Andrade-Lima \& Rocha 1971). No entanto, nestas áreas é comum ocorrer uma vegetação que assume uma fisionomia savânica, que apresenta predominantemente espécies oriundas do Cerrado, conhecida como cerrado costeiro (Moro et al. 2015). A vegetação da área de estudo pode ser classificada como Floresta Estacional Semidecidual das Terras Baixas (IBGE 2012).

$\mathrm{O}$ estudo foi realizado por meio de pesquisa de campo e da análise de exsicatas. A pesquisa de campo constitui-se de observações das populações in situ e da coleta de espécimes em estágio reprodutivo. Durante a coleta foi realizado o geo-referenciamento, com inclusão das informações obtidas na ficha de coleta da amostra. Essa etapa foi realizada entre julho de 2014 e junho de 2015, segundo metodologia usual em taxonomia vegetal empregada por Fidalgo \& Bononi (1989). O material coletado foi depositado no Herbário Lauro Pires Xavier (JPB). 
A análise das exsicatas foi realizada conforme Thiers (continuamente atualizado). Observou-se materiais depositados no Herbário JPB, além de amostras proveniente de outros herbários nacionais: Herbário Jayme Coelho de Moraes, Universidade Federal da Paraíba (EAN).

A identidade das espécies foi estabelecida através de suas diagnoses originais e comparação com o material tipo e fotografias ou imagens digitais dos mesmos depositados nos herbários K, P, RB e SP. As abreviações dos nomes dos autores das espécies foram feitas de acordo com Brummitt \& Powel (1992). As chaves de identificação foram elaboradas baseando-se nas características morfológicas mais diagnósticas. A terminologia morfológica usada nas diagnoses se baseou em Radford et al. (1974). Para as descrições genéricas e específicas foram analisadas as amplitudes das variações morfológicas dos materiais coletados na Mata do Buraquinho.

Para identificação dos táxons utilizou-se ainda literatura especializada, destacando-se Lewis (1987), Krapovickas \& Gregory (1994), Fernandes (1996), Pennington (2003), Lima et al. (2006), Costa et al. (2008), Fortuna-Perez (2009), Souza Costa (2006), Souza et al. (2012). Sempre que possível foram analisadas as descrições originais. A classificação dos táxons está de acordo com Lewis et al. (2005).

\section{Resultados e Discussão}

A tribo Dalbergieae está representada na Mata do Buraquinho por 11 espécies, distribuídas em sete gêneros. Os gêneros mais diversos foram Stylosanthes Sw. (3 spp.), seguido por Aeschynomene L. e Andira Lam. com (2 spp.) cada, respectivamente, e Arachis L., Machaerium Pers., Pterocarpus Jacq. e Zornia J.F. Gmel. com (1 sp.) cada. Ainda, foram encontrados quatro novos registros para a Paraíba, constituídos pelas espécies Aeschynomene evenia C. Wright, Andira legalis (Vell.) Toledo, Arachis pintoi Krapov. \& W. C. Greg. e Stylosanthes gracilis Kunth.

As espécies foram encontradas em quatro tipos distintos de fitofisionomias: floresta, Cerrado costeira, zona antropizada e margens de corpos de água. Todas as espécies de Stylosanthes, bem como Andira nitida Mart. ex Benth. e Aeschynomene viscidula Michx. ocorrem na área de Cerrado Costeira; Andira legalis (Vell.) Toledo, Machaerium hirtum (Vell.) Stellfeld e Pterocarpus rohrii Vahl, foram encontras apenas no interior da floresta; Arachis pintoi Krapov. \& W.C. Greg. e Aeschynomene evenia C. Wright ocorreram exclusivamente nas margens dos corpos de água. Por fim, Zornia latifolia $\mathrm{Sm}$. foi registrada no ambiente mais perturbado.

Tratamento taxonômico

\section{Dalbergieae Bronn ex DC.}

Árvore, erva ou subarbusto decumbente ou ereto. Estípula, base fixa, peltada, parcialmente adnata ao pecíolo em forma de bainha, ou livre, estreitamente triangular, lanceolada, margem inteira ou ciliada, caduca ou persistente. Folhas alterna, pari ou imparipinadas; bi-tri-tetra-penta ou pluri-folioladas; folíolos alternos ou opostos, lanceolado a oblongos, elíptico-obovado, ápice arredondado-mucronado, obtuso, retuso, margem inteira ou ciliada, plana ou revoluta, base arredondada, base aguda, assimétrica, face adaxial glabra, face abaxial glabra, pubescente, rufo-serícea, membranáceo ou coriáceo, concolores ou discolores; peciolada, pubescente; raque presente; estipela presente ou ausente. Inflorescência axilar ou terminal, espiciforme laxa ou congesta, racemo, panícula; bráctea caduca ou persistente. Flor séssil ou pedicelada, bractéola presente, monoica, zigomorfa, bractéola peltada ou basefixa, hipanto inconspícuo ou longo; cálice campanulado, radiado ou bilabiado, lacínios 4-5, persistente ou caduco no fruto; corola papilionácea, pétalas 5 , unguiculadas, amarelas, lilases ou roxas; estandarte orbicular, obovado-orbicular, obovado, patente, guia de néctar presente ou ausente; pétalas das alas livres, obovadas; pétalas da quilha unidas, oblongo-falcadas, falcada; androceu diadelfo ou monadelfo, estames 10, anteras homomórficas ou heteromórficas; ovário séssil ou estipitado, pluriovulado. Fruto baga, lomento, sâmara com núcleo seminífero basal ou central, estipitado ou séssil.

Chave de identificação para gêneros de Dalbergieae da Mata do Buraquinho, PB, Brasil

1. Estípula adnata ao pecíolo

2. Erva prostrada, folha tetrafoliolada, inflorescência axilar, hipanto até 10 vezes maior que a bráctea, antera heteromórfica, fruto geocárpico . 3. Arachis

2. Subarbusto ereto, folha trifoliolada, inflorescência terminal, hipanto menor que a bráctea, antera homomórfica, fruto não geocárpico 6. Stylosanthes 
1. Estípula não adnata ao pecíolo

3. Folha bifoliolada, folíolos com glândulas, bractéolas peltadas

7. Zornia

3. Folha 5-foliolada ou plurifoliolada, folíolos sem glândulas, bractéolas não peltadas

4. Subarbusto, fruto lomento 1. Aeschynomene

4. Árvore, fruto sâmara ou drupa

5. Folíolos opostos, estipela presente, fruto drupa

2. Andira

5. Folíolos alternos, estipela ausente, fruto sâmara

6. Planta armada, folíolo estreito-oblongo a linear, ápice retuso, pétalas lilases, sâmara com núcleo seminífero basal, 0,6-0,8 cm larg.

4. Machaerium

6. Planta inerme, folíolo elíptico-oblongo, ápice cuspidado, pétalas amarelas, sâmara com núcleo seminífero central, 3,4-3,6 cm larg. 5. Pterocarpus

Chave de identificação para espécies de Dalbergieae da Mata do Buraquinho, PB, Brasil

1. Hábito arbóreo

2. Folíolos alternos, flor com pétalas amarelas, sâmara com núcleo seminífero central, nunca drupa

7. Pterocarpus rohrii (fig. $4 \mathrm{c}-\mathrm{d}$ )

2. Folíolos opostos, flor com pétalas lilases ou rosa, sâmara com núcleo seminífero basal ou fruto drupa

3. Ramos armados, estipelas ausentes, fruto sâmara

6. Machaerium hirtum (fig. $4 \mathrm{a}-\mathrm{b}$ )

3. Ramos inermes, estipelas presentes, fruto drupa

4. Ramos glabros, folíolo com ápice agudo, margem plana, face abaxial glabra

4. Andira nitida (fig. 3a-b)

4. Ramos rufo-tomentosos, folíolo com ápice obtuso-retuso, margem revoluta, face abaxial rufo-serícia 3. Andira legalis (fig. $2 \mathrm{c}-\mathrm{d}$ )

1. Hábito herbáceo, arbustivo, subarbustivo, trepador

5. Folha bifoliolada, bractéolas peltadas

11.Zornia latifolia (fig. 5 c-d)

5. Folha tri-tetra-plurifoliolada, bractéola não peltada ou ausente

6. Pecíolo não adnato a estípula, inflorescência racemiforme

7. Planta decumbente, ramos híspidos, estípula basefixa, até 9 folíolos, lomento com segmentos orbiculares, estípite $0,1-0,2 \mathrm{~cm}$ compr.

2. Aeschynomene viscidula (fig. 2c-d)

7. Planta ereta, ramos glabros, estípula peltada, com mais de 9 folíolos, lomento com segmento de fruto quadrado, estípite $0,6-0,8 \mathrm{~cm}$ compr. 1. Aechynomene evenia (fig. 2 a-b)

6. Pecíolo adnato a estípula, inflorescência espiciforme

8. Folha 4-foliolada, cálice bilabiado, anteras heteromórficas

8. Folha 3-foliolada, cálice radiado, anteras homomórficas

9. Indumento hirsuto, folíolos com face adaxial glabra, brácteas com longas cerdas

10. Stylosanthes gracilis (fig. $4 \mathrm{f}-\mathrm{h}$ )

9. Indumento seríceo ou pubescente, folíolos com face adaxial seríceo ou pubescente, brácteas não cerdosas

10. Planta não viscosa, folíolos com nervuras secundárias 7-9, vistosas, estandarte sem estrias vermelhas 8. Stylosanthes capitata (fig. 4e)

10. Planta viscosa, folíolos com nervuras secundárias 2-3, não vistosas, estandarte com estrias vermelhas 9. Stylosanthes viscosa (fig. 5a-b)

1. Aeschynomene evenia C. Wright, Anales Acad. Ci. Med. Habana, 5: 334-335. 1869.

Figuras $2 a-b$

Subarbusto ereto, ca. $1 \mathrm{~m}$ alt.; ramo cilíndrico, estriado, glabrescente, inerme. Estípula $0,7-0,8 \times 0,1 \mathrm{~cm}$, não adnata ao pecíolo, estreitamentetriangular, glabra, caduca, peltada, margem inteira. Folha paripinada; 12-26-foliolada; folíolos
0,3-1,3 × 0,1-0,2 cm, opostos, oblongos, ápice arredondado-mucronado, margem inteira, base aguda, face adaxial e abaxial glabra, membranáceos; pecíolo 0,3-1,1 cm compr., glabro, raque 1-5,3 cm compr., sem pulvínulo, estipela ausente. Inflorescência axilar, racemiforme, laxa, 2,4-3,5 cm compr.; pedúnculo 0,7-1,1 cm compr.; bráctea não vista. Flor brevepedicelada, 0,3-0,7 cm compr.; bractéola triangulares, 
cálice bilabiado, lacínios 5; pétalas amarelas, estandarte reflexo, orbicular, alas oblongas, livres, pétalas da quilha falcadas; androceu diadelfo, anteras homomórficas; ovário estipitado, pluriovulado. Fruto lomento, 1,2-4,2 × 0,4-0,5 cm, longo-estipitado 0,6-0,8 cm compr., linear, plano, 2-8 segmentos quadrados, glabro.

Material examinado: BRASIL. PARAÍBA: João Pessoa, Jardim Botânico, 18-X-2006, fl. e fr., P.C. Gadelha Neto 1610 (JPB); idem, 15-VII-1992, fl. e fr., M.S. Pereira 22 (JPB); idem, 21-VIII-2006, fl., P.C. Gadelha Neto 1570 (JPB).

Aeschynomene evenia tem como características diagnósticas o cálice marcadamente bilabiado, folhas com movimentos násticos. Pode ser distinguida de A. viscidula por apresentar o hábito ereto, ramos glabros, estípulas peltadas e frutos com segmentos quadrados (vs. o hábito decumbente, ramos híspidos, estípula basefixa, frutos com segmentos orbiculares). Seus indivíduos têm preferência por ambientes parcialmente alagados. De acordo com Fernandes (1996), esta espécie está distribuída na Bolívia, Brasil, Cuba, Estados Unidos, Haiti, Panamá, República Dominicana e Venezuela. Com relação a distribuição no Brasil, segundo o BFG (2015) A. evenia ocorrem em praticamente todos os Estados do nordeste do Brasil, exceto no Rio Grande do Norte e Paraíba, sendo, portanto, este registro novo para este último Estado.

2. Aeschynomene viscidula Michx., Fl. Bor.-Amer., 2: 74-75. 1803.

Figuras 2c-d

Subarbusto decumbente; ramo cilíndrico, laxo, levemente estriado, híspido, tricomas glandulares, inerme. Estípula $0,2-0,3 \times 0,1-0,15 \mathrm{~cm}$, não adnata ao pecíolo, triangular, basefixa, margem ciliada. Folha imparipinada; 7-9-foliolada; folíolos 0,4-0,5 × 0,3-0,5 cm, opostos, obovados, ápice obtusomucronado, margem ciliada, base assimétrica, face adaxial glabra, face abaxial esparsamente-vilosa;
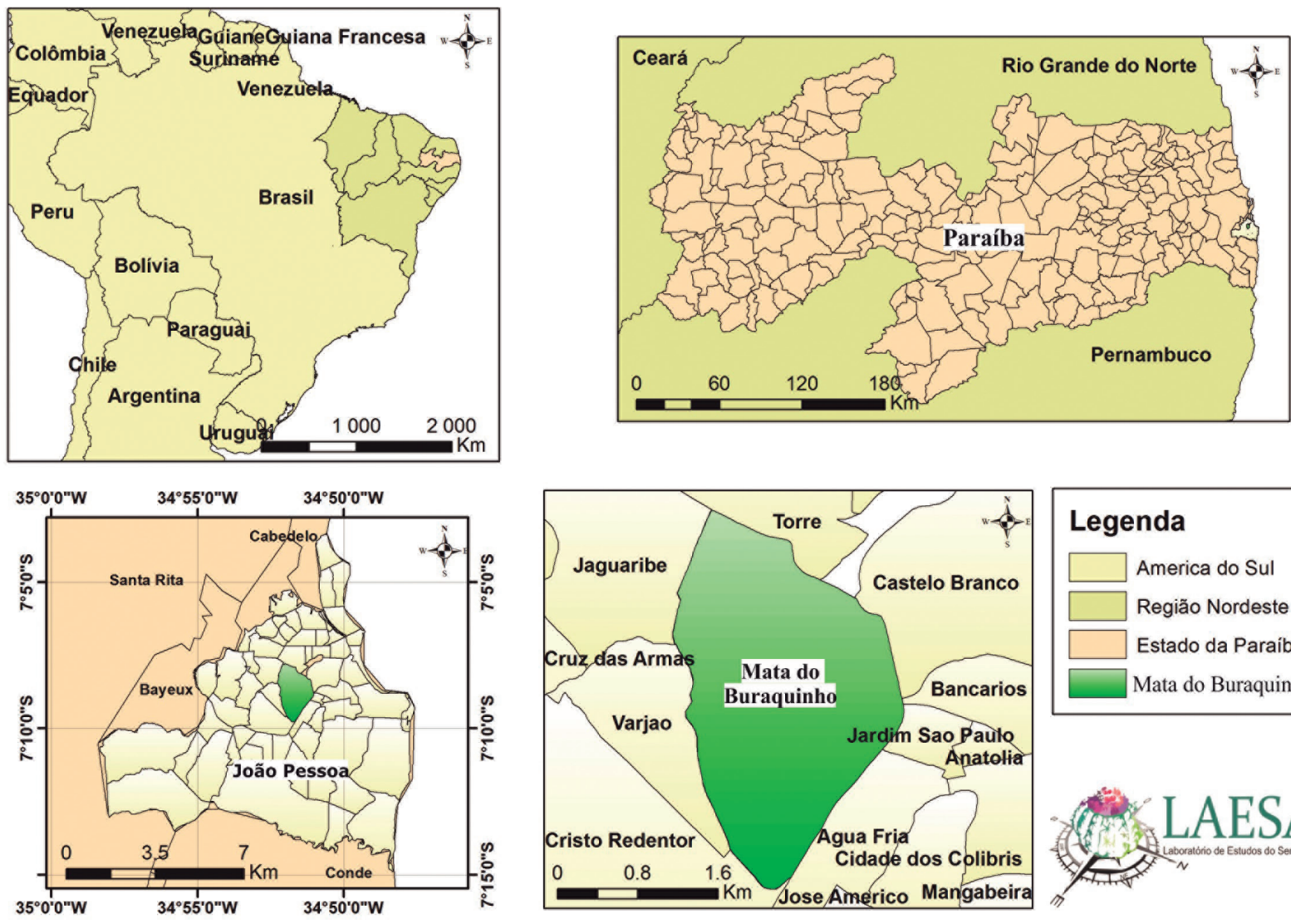
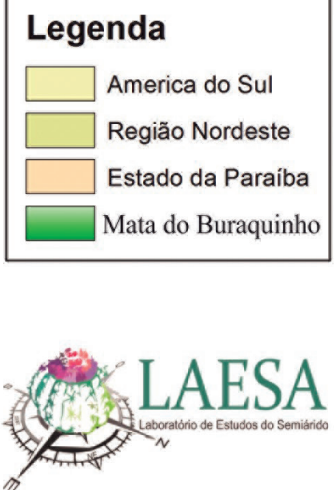

Figura 1. Localização da Mata do Buraquinho no município de João Pessoa, Paraíba, Brasil.

Figure 1. Location of Mata do Buraquinho in the municipality of João Pessoa, Paraíba State, Brazil. 
pecíolo 0,8-1,0 cm compr., hirsuto, cilíndrico; raque 0,6-0,8 cm compr., estipela ausente. Inflorescência axilar, 4-6 cm compr., pedúnculo 1,2-1,8 cm compr.; bráctea persistente, bractéola $2 \times 1 \mathrm{~cm}$, ovada, indumento hirsuto. Flor pedicelada, 0,9-1,2 cm compr.; bractéolas ovadas, cálice radiado, persistente, lacínios 5; pétalas amarelas; estandarte orbicular, alas obovadas, livre, pétalas da quilha falcadas; androceu diadelfo, anteras homomórficas; ovário súpero, pluriovulado. Fruto lomento, 0,8-1,4×0,3 cm, brevemente-estipitado 0,1-0,2 cm compr., plano, oblongo, 2-3 segmentos, orbiculares, cartáceo. Semente $0,2 \times 1,5 \mathrm{~mm}$, ovada, hilo basal, cor castanha, testa mole.

Material examinado: BRASIL. PARAíBA: João Pessoa, Mata do Buraquinho, 17-X-2012, fl. e fr., P.C. Gadelha Neto et al. 3363 (JPB); idem, 22-IX-2004, fl., P.C. Gadelha Neto 1274 (JPB); idem, fl. e fr., 8-V-1953, M. Xavier s.n. (JPB 138).

Aeschynomene viscidula apresenta como características diagnósticas a presença de indumento híspido com tricomas glandulares que tornam a planta viscosa. Morfologicamente é mais próxima de $A$. evenia (ver comentário supracitado). Tem preferência por ambientes menos úmidos, associada a lugares abertos e arenosos. De acordo com Fernandes (1996) esta espécie ocorre nas Antilhas, Brasil, Cuba, El Savador, Estados Unidos, Guatemala, Honduras, Pequenas Antilhas, México e Venezuela. Segundo a BFG (2015) para o Brasil esta espécie está presente em todo Nordeste, exceto no Estado do Maranhão, encontrada na Caatinga, Cerrado, Cerrados costeiras e Restinga.

3. Andira legalis (Vell.) Toledo, Arq. Bot. estado São Paulo, 2: 29. 1946.

Figuras 2e-f

Árvore ca $30 \mathrm{~m}$ alt.; ramo estriado, rufo-tomentoso, inerme. Estípula $0,6 \times 0,3 \mathrm{~cm}$, não adnata ao pecíolo, lanceolada, rufo-tomentosa, persistente, basefixa, margem inteira. Folha imparipinada, 5-9-foliolada; folíolo 4-9,3 × 2,5-5,2 cm, oposto, oblongo-obovado, base obtusa, ápice obtuso-retuso, margem inteira, revoluta, face adaxial glabra, face abaxial rufo-serícea, venação secundária expressa na face abaxial, coriáceo, discolor; pecíolo 8,5-11,5 cm compr., tomentoso, canaliculado; raque 3,4-14,5 cm compr.; pulvínulo 0,4-0,6 cm compr.; estipela 0,2-0,4 cm compr. Inflorescência terminal, panícula, multiflora, rufotomentosa, bráctea lanceolada, caduca. Flor breve- pedicelada, bractéola estreitamente triangular, caduca, cálice radiado rufo, lacínios 4 , triangulares; pétalas roxas; estandarte ovado, reflexo, ala subfalcada, livre, pétalas da quilha unidas; androceu diadelfo, anteras homomórficas; ovário estipitado, pauciovulado. Fruto drupa, 6,6 -7,7 × 6,0-6,3 cm, ovado, escabroso, cinza.

Material examinado: BRASIL. PARAíBA: João Pessoa, Mata do Buraquinho, 9-IX-2012, fl., P.C. Gadelha Neto 3360 (JPB).

Material adicional: BRASIL. PARAíba: João Pessoa, Jacarapé, 6-I-1993. fr., O.T. Moura 942 (JPB).

Andira legalis apresenta como características diagnósticas estípula persistente, indumento rufotomentoso presente nos ramos, nas estípulas e nas faces abaxial dos folíolos e margem foliolar revoluta vs. A. nitida estípula caduca; indumento rufo-tomentoso ausente nos ramos, estípulas e faces abaxiais dos folíolos, estes apresentam a margem plana. Na área estudada foram encontradas apenas essas duas espécies deste gênero. Andira legalis é uma espécie que ocorreu apenas no interior da mata, no entanto podem ser encontradas nos Cerrados costeiras. De acordo com Pennington (2003) esta espécie é endêmica do Brasil. Esta espécie tem distribuição restrita aos Estados do Rio de Janeiro, Espírito Santo, Minas Gerais, Bahia e Pernambuco, com ocorrência exclusiva a Mata Atlântica (BFG 2015).

4. Andira nitida Mart. ex Benth., Comm. Legum. Gen., 45. 1837.

Figuras $3 \mathrm{a}-\mathrm{b}$

Árvore ca. $4 \mathrm{~m}$ alt.; ramo cilíndrico, glabro, cinza, inerme. Estípula $0,5 \times 0,05 \mathrm{~cm}$, não adnata ao pecíolo, estreitamente-triangular, caduca, basefixa, margem inteira. Folha imparipinada; 5-7-foliolada; folíolo 2,5-9,9 × 2,4-5,5 cm, oposto, oblongo, ápice agudo, margem inteira, plana, base obtusa, face adaxial e abaxial glabras, coriácea, concolor, venação central proeminente, coriáceo; pecíolo 4,2-5,3 cm compr., glabro, canaliculado; raque 1,8-7,4 cm compr.; pulvínulo 0,2-0,7 cm compr.; estipela $0,1 \mathrm{~cm}$ compr. Inflorescência terminal ou axilar, panícula, bráctea caduca. Flor pedicelada 0,1-0,2 cm compr.; bractéola triangular; cálice radiado, escuro, lacínios 5 , pétalas roxas; estandarte orbicular, reflexo, alas livres, obovadas, pétalas da quilha falcadas; androceu diadelfo, estames 10, anteras homomórficas; ovário estipitado, pauciovulado. Fruto drupa, 3,4-6,7 × 3-4,9 cm, elíptico ou oblongo, cilíndrico, glabro. 

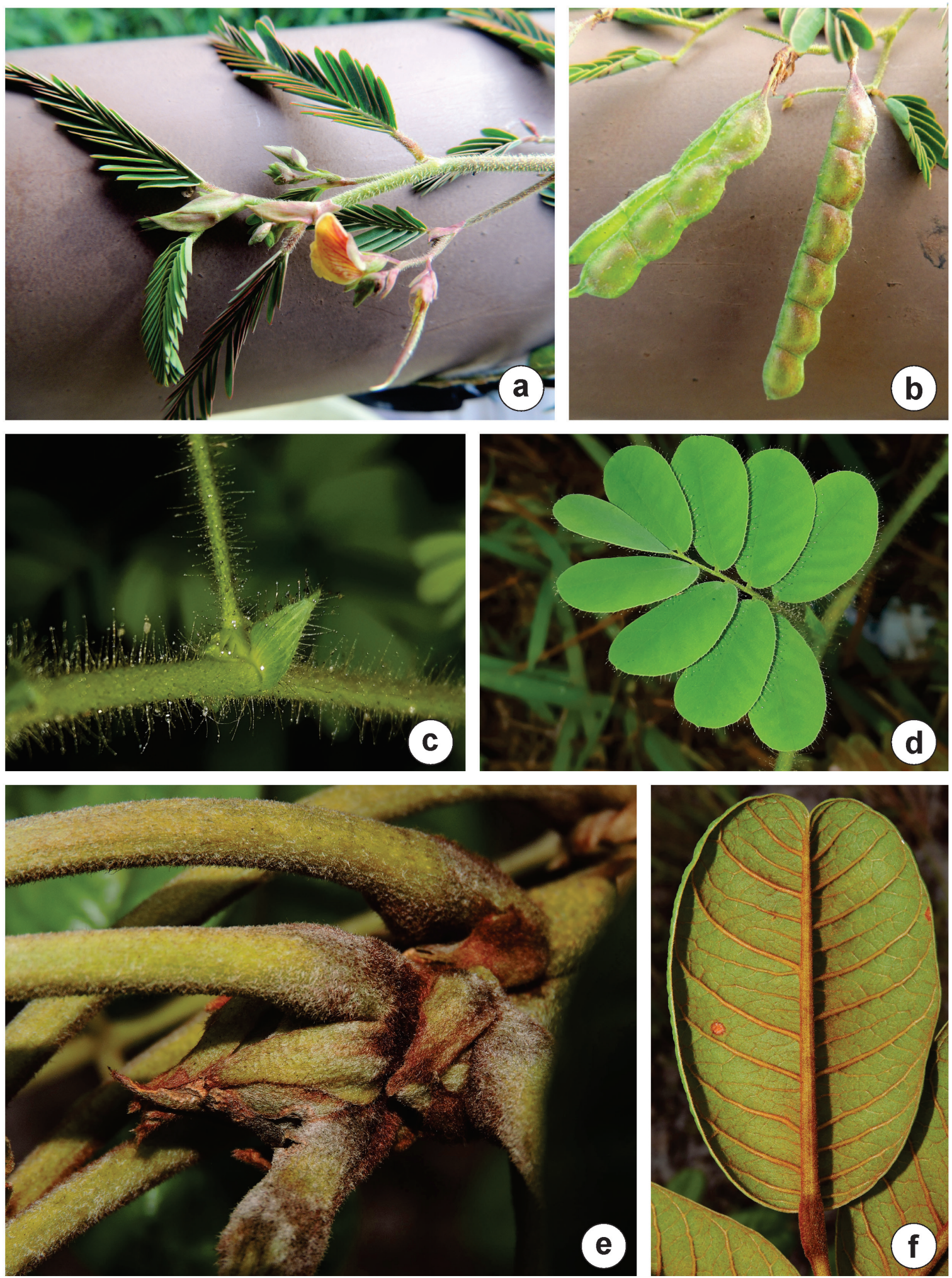

Figura 2. a-b. Aeschynomene evenia. a. Ramo cilíndrico com estipula peltada. b. Lomento estipitado e segmentos quadrados. c-d. $A$. viscidula. c. Estípula basefixa e margem ciliada. d. Folha composta com folíolos alternos, obovados. e-f. Andira legalis. e. Ramo tomentoso com estípula persistente. f. Folíolo oblongo, ápice retuso, margem revoluta e face abaxial tomentulosa. Fotos: Rubens Queiroz.

Figure 2. a-b. Aeschynomene evenia. a. Cilindrical branch with peltate stipule. b. Stipitate loment and squarish segments. c-d. A. viscidula. c. Basifixed stipule and ciliate border. d. Compound leaf with obovate and alternate leaflets. e-f. Andira legalis. e. Tomentose branch with persistent stipule. f. Oblong leaflet, retuse apex, revolute leaf border and tomentose abaxial surface. Photos: Rubens Queiroz. 

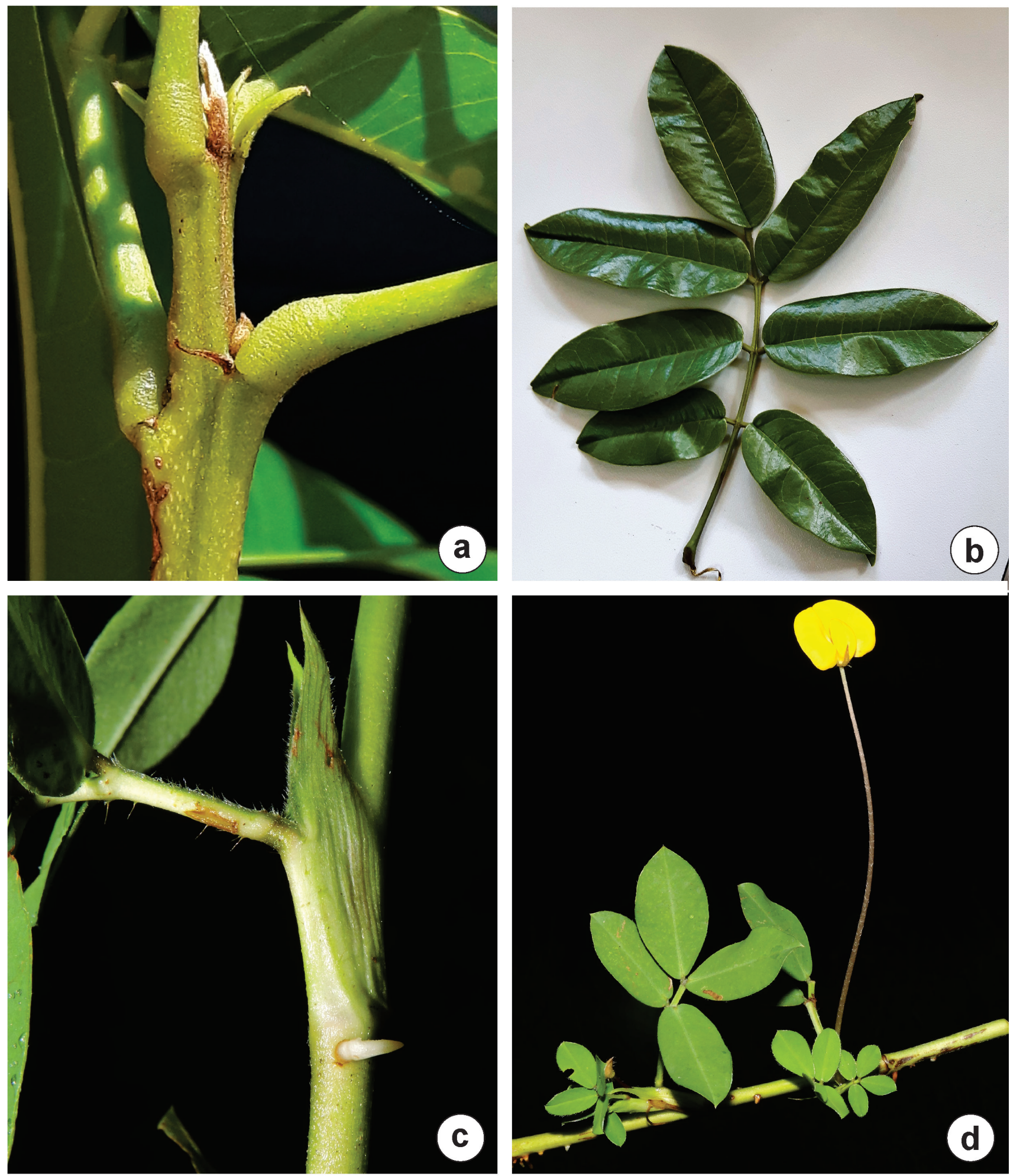

Figura 3. a-b. Andira nitida. a. Ramo glabro com estípulas caducas. b. Folha imparipinada com folíolos opostos glabros. c-d. Arachis pintoi. c. Estípula adnata ao pecíolo. d. Folha tetrafoliolada, hipanto com comprimento maior que a folha. Fotos: Rubens Queiroz.

Figure 3. a-b. Andira nitida. a. Glabrous branch with caducous stipule. b. Imparipinnate leaf with opposite glabrous leaflets. c-d. Arachis pintoi. c. Stipule adnate to the petiole. d. Tetrafoliolate leaf, hypanthium longer than the leaf. Photos: Rubens Queiroz. 
Material examinado: BRASIL. PARAíbA: João Pessoa, Mata do Buraquinho, 16-VII-1994, fl., A.C.A. Moura 87 (JPB); idem, 2-XI-2003, fl. P.C. Gadelha Neto 1065 (JPB).

Andira nitida é facilmente reconhecida por apresentar estípulas caducas, folhas imparipinadas e folíolos opostos com estipelas presentes, sendo seus folíolos glabros com margem plana. De acordo com Pennington (2003), esta espécie é endêmica do Brasil. Segundo o BFG (2015) esta espécie é restrita a Mata Atlântica, ocorrendo nos Estados do Rio de Janeiro, Espírito Santo, Bahia, Sergipe, Alagoas, Pernambuco, Paraíba e Rio Grande do Norte.

5. Arachis pintoi Krapov. \& W. C. Greg., Bonplandia (Corrientes), 8: 81-83, f. 2. 1994.

Figuras $3 \mathrm{c}-\mathrm{d}$

Erva, decumbente; ramo laxo, verde, hirsuto. Estípula $0,4-2,8 \times 0,1-0,4 \mathrm{~cm}$, adnata ao pecíolo formando uma bainha, parte livre 0,5-1,6 cm compr., parte adnata ao pecíolo $0,8-1,5 \mathrm{~cm}$ compr., triangular, hirsuta, persistente. Folhas paripinadas, 4-folioladas; folíolo 1,3-4 × 0,5-1,8 cm, oposto, oblongo-obovado, ápice arredondado-mucronado, margem inteira hirsuta, base assimétrica, face adaxial e abaxial glabra, venação central proeminente, membranáceo, concolor; pecíolo 1,6-5 cm compr., hirsuto, canaliculado; raque 0,4-1,1 cm compr.; pulvínulo ausente; estipela ausente. Inflorescência axilar, espiciforme, brácteas lineares. Flor séssil, hipanto longo; bractéola ausente, cálice bilabiado, lacínios 4, pétalas amarelas, estandarte orbicular, alas obovadas, livres, pétalas da quilha falcadas; androceu diadelfo, anteras heteromórficas; ovário séssil. Fruto não observado.

Material examinado: BRASIL. PARAíbA: João Pessoa, Mata do Buraquinho, 9-V-2015, fl., P.C. Gadelha Neto 4009 (JPB); idem, 26-X-2013, fr., P.C. Gadelha Neto 3668 (JPB).

Arachis pintoi apresenta como características diagnósticas hábito herbáceo, ramos prostrados com raízes adventícias nos nós, estípula adnata ao pecíolo, folhas tetrafolioladas, pecíolo hirsuto, e frutos geocárpicos. Esta espécie apresenta preferência por ambiente paludoso na margem do riacho. Segundo Krapovickas e Gregory (1994), embora endêmica do Brasil, representantes podem ser encontrados em outras localidades, pois é uma planta ornamental, popularmente conhecida como grama amendoim. De acordo com a BFG (2015) esta espécie ocorre apenas nos Estados de Minas Gerais, Goiás e Bahia, sendo este o primeiro registro para a Paraíba.

6. Machaerium hirtum (Vell.) Stellfeld, Tribuna Farm., 12: 132. 1944.

Figuras $4 \mathrm{a}-\mathrm{b}$

Árvore $7 \mathrm{~m}$ alt.; ramo cilíndrico, tomentuloso, armado. Estípula 0,2-0,5 × 0,1-0,2 cm, não adnata ao pecíolo, estreitamente-triangular, persistente, basefixa, espinescente. Folhas imparipinadas, 37-41-foliolada; folíolo 0,2-0,4 × 0,5-1,6 cm, alterno, estreitamenteoblongo a linear, ápice retuso, margem proeminente, base assimétrica, face adaxial e abaxial glabra, oposto, membranáceo, concolor; pecíolo $0,5-1 \mathrm{~cm}$ compr., puberulento; raque 6-9 $\mathrm{cm}$ compr.; pulvínulo 0,1 cm compr.; estipela ausente. Inflorescência axilar ou terminal, panícula, bráctea triangular. Flor brevepedicelada 0,1-0,3 cm compr.; bractéola ovada, cálice radiado, enegrecido, lacínios 5, curtos; pétalas lilases, estandarte orbiculado, reflexo, alas livres, falcado-oblongas, pétalas da quilha falcadas, androceu monadelfo, anteras homomórficas; ovário estipitado, uniovulado. Fruto sâmara 4,6-5 × 0,6-0,8 cm, núcleo seminífero basal, liso, estipe, $0,7 \mathrm{~cm}$ compr., arredondado mucronado, oblongo.

Material examinado: BRASIL. PARAíBA: João Pessoa, Jardim Botânico, 22-X-2002, fl. e fr., P.C. Gadelha Neto 791 (JPB).

Material adicional: BRASIL. PARAíba: João Pessoa, Mata, 19-III-2010. fl., A.H.L. Cariri 128 (JPB).

Machaerium hirtum têm como características diagnósticas a presença de ramos tomentulosos, armados, folíolos estreitamente-oblongos a linear com ápice retuso e frutos sâmara com núcleo seminífero basal. Frequente na área estudada, presente principalmente em ambiente de borda da área antropizada. Segundo Fillardi (2013) esta espécie apresenta a seguinte distribuição: Argentina, Bolívia, Brasil, Colômbia, Guiana, Panamá, Paraguai, Peru e Venezuela. No Brasil tem ampla distribuição geográfica, ocorrendo em todos os Estados (BFG 2015).

7. Pterocarpus rohrii Vahl, Symb. Bot. 2: 79-80. 1791.

Figuras 4c-d

Árvore $12 \mathrm{~m}$ alt.; ramo levemente, estriado, glabro, inerme. Estípula 0,2-0,3 × 0,1 cm compr., não adnata ao pecíolo, triangular, glabra, basefixa. 

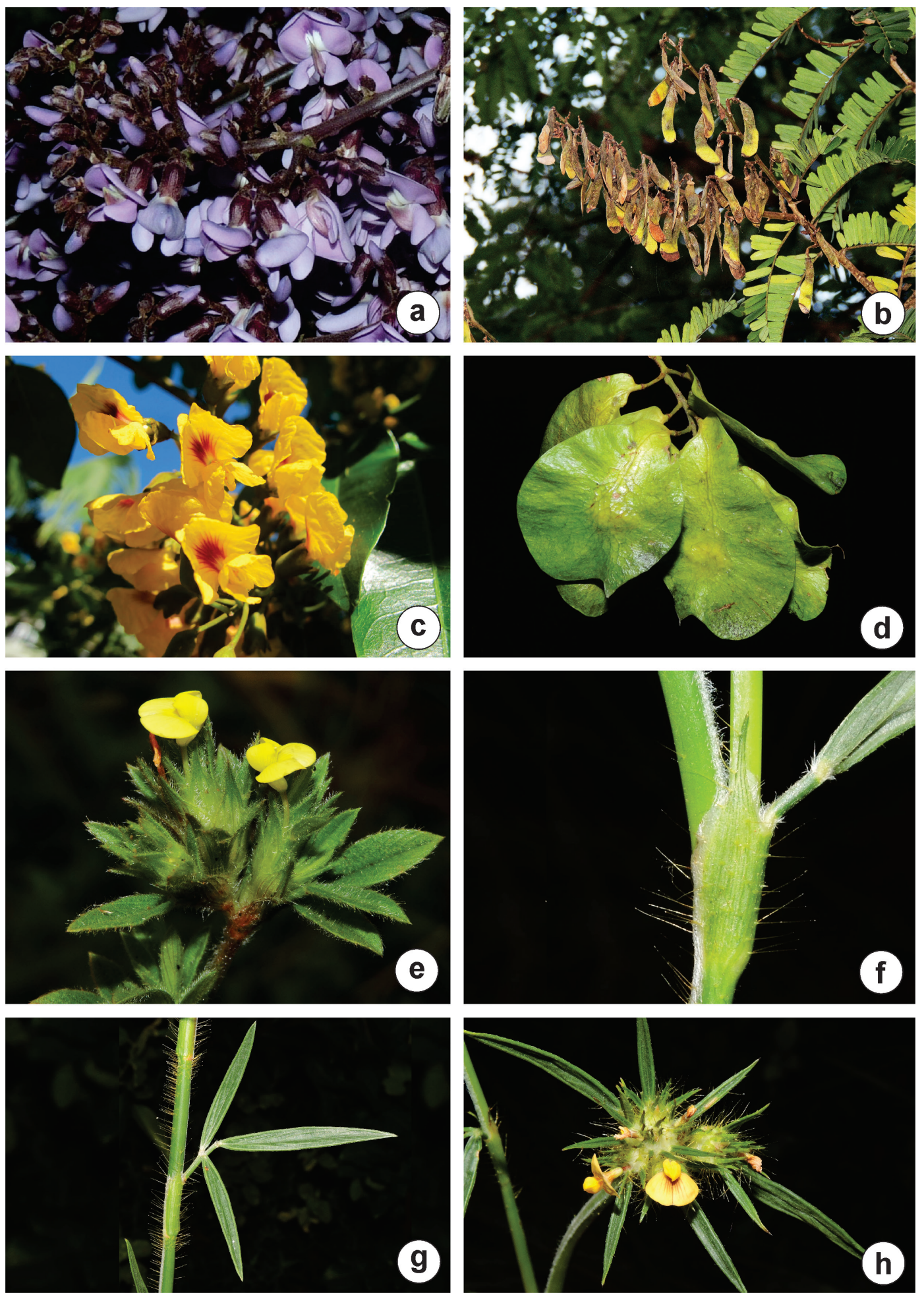

Figura 4. a-b. Machaerium hirtum. a. Inflorescência com flores lilases. b. Sâmaras com núcleos seminíferos basais. c-d. Pterocarpus rohrii. c. Corola papilionácea amarela. d. Sâmara com núcleo seminífero central. e. Stylosanthes capitata. e. Inflorescência terminal, espiga. f-h. Stylosanthes gracilis. f. Estípula adnata ao pecíolo com tricoma glandular. g. Folha trifoliolada com folíolos glabros. h. Espigas com brácteas foliáceas. Fotos: Rubens Queiroz.

Figure 4. a-b. Machaerium hirtum. a. Inflorescence with lilac flowers. b. Samaras with basal seminiferous nuclei. c-d. Pterocarpus rohrii. c. Yellow papilionaceous corolla. d. Samara with a central seminiferous nucleus. e. Stylosanthes capitata. e. Terminal inflorescence, spike. f-h. Stylosanthes gracilis. f. Stipule adnate to the petiole with a glandular hair. g. Trifoliolate leaf with glabrous leaflets. h. Spike with foliate bracts. Photos: Rubens Queiroz. 
Folhas imparipinadas, 5-folioladas; folíolo 5,2-11,6 × 2,6-4,9 cm, alterno, elíptico-oblongo, ápice cuspidado, margem inteira, base arredondada, venação central proeminente, face adaxial e abaxial glabras, concolor, coriáceo; pecíolo 3,3-3,7 cm compr., glabro, cilíndrico, estriado; raque 7,1-9,5 cm compr.; pulvínulo $0,2 \mathrm{~cm}$ compr.; estipela ausente. Inflorescência axilar, pseudorracemo, $5 \mathrm{~cm}$ compr., pedúnculo $2,3 \mathrm{~cm}$ compr., bráctea não vista. Flores pediceladas, bractéolas estreitamente-triangulares, cálice bilabiado, tomentuloso, rufo, lacínios 5, triangulares; pétalas alaranjadas; estandarte orbicular, reflexo, ápice retuso, margem crenada, base com guia de néctar vinho; alas livres, obovadas; pétalas da quilhas aderidas; androceu monadelfo, anteras homomórficas; ovário estipitado, uniovulado. Fruto sâmara, 3,9-4,7 × 3,4-3,6 cm, núcleo seminífero central, glabro, castanho.

Material examinado: BRASIL. PARAíbA: João Pessoa, Jardim Botânico, 20-I-2012, fl., P.C. Gadelha Neto 3146 (JPB).

Material adicional: BRASIL. Paraíba: João Pessoa, 24-II-2005. fl., E.A. Rocha 1361 (JPB.). Idem. Mangabeira, Rio do Cabelo, 22-II-2011, fl., L.A. Pereira 165 (JPB).

Pterocarpus rohrii quando adulta é composta por tronco cinza com ritidoma destacando-se em placas cinéreas, ramos glabros, folha com folíolos glabros em ambas faces e frutos sâmaras com núcleo seminífero central, glabros. $\mathrm{Na}$ área estudada esta espécie ocorre no interior da floresta, formando uma grande população de árvores de dossel. Apresenta ampla distribuição nas Américas, ocorrendo desde Vera Cruz, no México, até Santa Catarina, no Brasil (Rojo 1972). No Brasil, sua distribuição é muito abrangente em áreas florestais, ocorrendo em todos os Estados da federação (BFG 2015).

8. Stylosanthes capitata Vogel, Linnaea 12: 70. 1838. Figura 4e

Subarbusto 0,5 m alt., ramo cilíndrico, seríceo, inerme, não viscoso. Estípula 1,4-1,5 cm compr., parcialmente adnata ao pecíolo formando uma bainha, parte livre $0,6-1 \times 0,1 \mathrm{~cm}$, estreitamente-triangular, adnata ao pecíolo 0,6-0,8 cm compr., serícea, persistente. Folhas imparipinadas, trifolioladas, folíolo 0,5-1,7 × 0,1-0,5 cm, oblongo-elíptico, ápice agudo, mucronado, margem, margem inteira, base aguda, face adaxial e abaxial seríceas, venação 7-9; pecíolo $0,7 \mathrm{~cm}$ compr., seríceo, canaliculado; raque 0,2-0,3 cm compr., pulvínulo ausente, estipela ausente. Inflorescência terminal, congesta, espiciforme, glomerular, 2-2,6 cm compr., bractéa persistente, 1,1-1,5 × 0,1-0,3 cm, elíptica. Flor séssil, exserta das brácteas; bractéolas lineares, basefixa, cálice bilabiado, lacínios 5; pétalas amarelas; estandarte orbicular, sem estrias vermelhas; alas obovadas; pétalas da quilha falcadas, androceu monadelfo, filetes curtos, anteras heteromórficas; ovário séssil, biovulado, estilete falcado. Fruto lomento, 0,3-0,4 ×0,2 cm, cálice persistente, 2-segmentado, angulado.

Material examinado: BRASIL. PARAÍBA: João Pessoa, Mata do Buraquinho, 26-IX-2011, fl. e fr., P.C. Gadelha Neto 3076 (JPB).

Stylosanthes capitata se caracteriza por apresentar ramos não congestos, folhas trifolioladas, venação expressa e vistosa e inflorescência terminal. Ocorre nas áreas mais abertas conhecidas como tabuleiros. De acordo com Souza Costa (2006), esta espécie ocorre no Brasil e na Venezuela. Segundo o (BFG 2015) tem ampla distribuição no Brasil, e ocorre em todos os Estados do nordeste.

9. Stylosanthes gracilis Kunth, Nova Genera et Species Plantarum (quarto ed.) 6: 507-508, pl. 596. $1823[1824]$.

Figuras 4f-h

Erva ereta, $70 \mathrm{~cm}$ alt.; ramo cilíndrico, hirsuto, rufo. Estípula parcialmente adnata ao pecíolo formando uma bainha, parte livre 0,5-0,7 $\times 0,1 \mathrm{~cm}$, estreitamentetriangular, parte adnata ao pecíolo 0,9-1,2 cm compr., hirsuta, persistente. Folhas imparipinadas, trifolioladas; folíolo 1,6-4,8 × 0,2-0,4 cm, estreitamente-romboide, ápice agudo-mucronado, margem inteira, base aguda, face adaxial e abaxial glabras, nervura na margem expressa, membranácea; pecíolo 1,2-2,1 cm compr., hirsuto; raque $2 \mathrm{~mm}$ compr.; pulvínulo ausente; estipela ausente. Inflorescência terminal, espiciforme, 0,6-1,5 cm compr., pedúnculo 2,3-8 cm compr.; bráctea 1-3,5 cm compr., apresentando longas cerdas. Flor séssil, bráctea linear., basefixa, persiste, cálice bilabiado, lacínios 5, pétalas amarelas; estandarte patente, orbicular, com estrias vermelhas; alas livres, obovadas; pétalas da quilha unidas, falcadas, base auriculada; androceu monadelfo, anteras heteromórficas; ovário séssil, biovulado, seríceo. Fruto lomento, cálice persistente, bissegmentado, estilete persistente curvado. 
Material examinado: BRASIL. PARAíbA: João Pessoa, Mata do Buraquinho, 9-X-2010, fl. e fr., P.C. Gadelha Neto et al. 2782 (JPB); idem, 3-VIII-2011, fl. e fr., P.C. Gadelha Neto 2991 (JPB).

Stylosanthes gracilis apresenta como características diagnósticas o hábito herbáceo, tricoma rufo-hirsuto; folha com folíolos glabros em ambas as faces e fruto bissegmentado. Ocorre na área cuja vegetação é do tipo Cerrado costeiro, tendo como principal componente o estrato herbáceo. De acordo com Souza Costa (2006), esta espécie ocorre na Bolívia, Brasil, Guiana Francesa, Panamá e Venezuela. Segundo o BFG (2015), no Brasil está presente
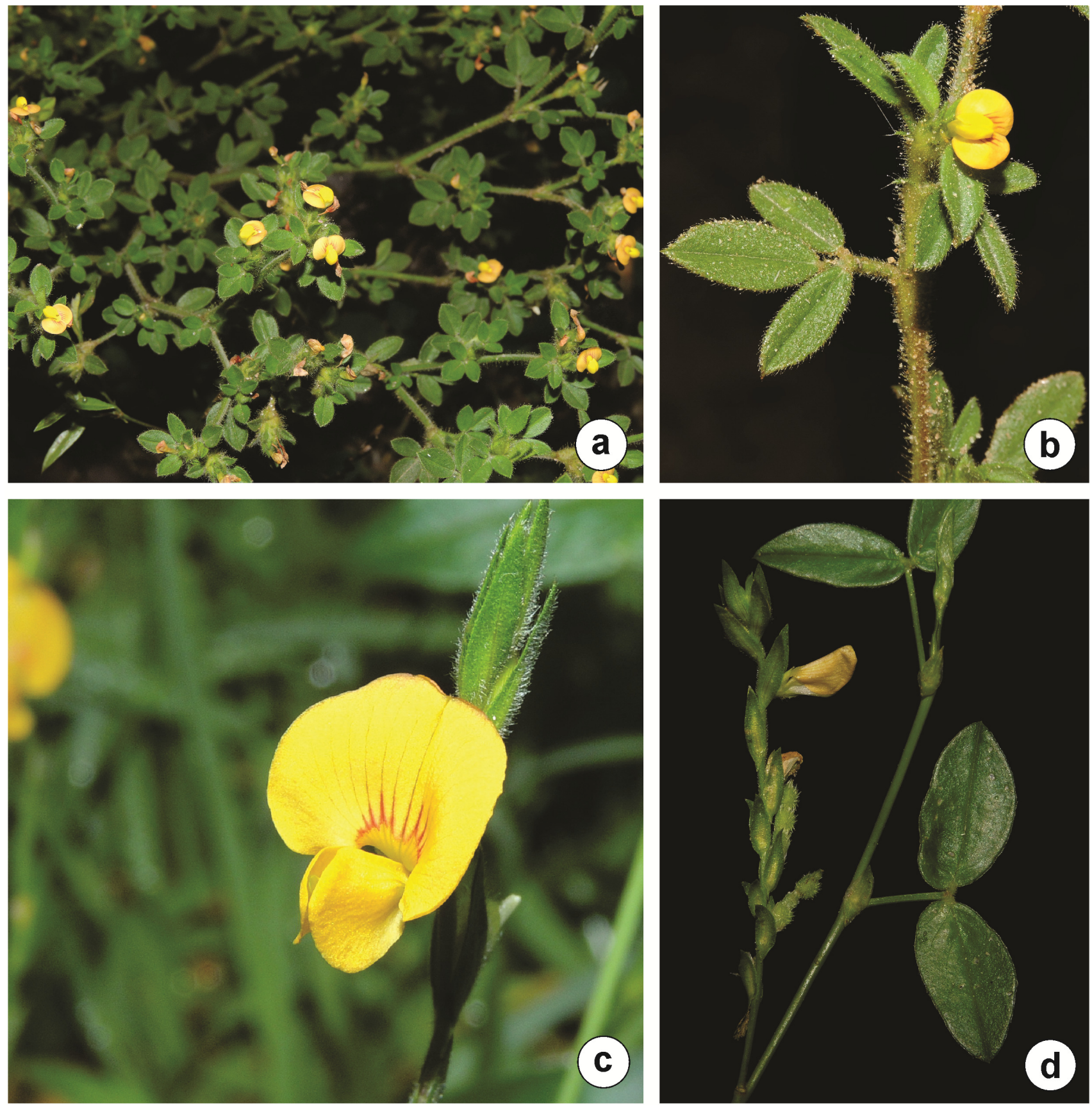

Figura 5. a-b. Stylosanthes viscosa. a. Ramos difusos e viscosos. b. Ramo com folha trifoliolada, espiga congesta. c-d. Zornia latifolia. c. Corola zigomorfa. d. Ramo reprodutivo com estípula peltada, folha bifoliolada, espiga laxa com bractéolas peltadas. Fotos: Rubens Queiroz.

Figure 5. a-b. Stylosanthes viscosa. a. Diffuse and viscous branches. b. Branch with a trifoliolate leaf and a congest spike. c-d. Zornia latifolia. c. Zygomorphic corolla. d. Reproductive branch with a peltate stipule, a bifoliolate leaf, a lax spike, and a peltate bracteole. Photos: Rubens Queiroz. 
praticamente em todos os Estados nordeste, exceto no Piauí, Rio Grande do Norte e Paraíba, sendo, portanto, uma nova ocorrência para o Estado da Paraíba.

10. Stylosanthes viscosa (L.) Sw., Prodr., 108. 1788. Figuras 5a-b

Subarbusto ereto, $60 \mathrm{~cm}$ de alt.; ramos difusos, cilíndricos, viscosos, pubescentes e esparso setosos. Estípula parcialmente adnata ao pecíolo formando uma bainha, parte livre 0,2-0,3 $\times 0,1 \mathrm{~cm}$, estreitamente-triangular, adnata ao pecíolo 0,5 $0,7 \mathrm{~cm}$ compr., pubescente, persistente, nervura pubescente. Folhas imparipinadas, trifolioladas; folíolo $0,4-1,1 \times 0,2-0,5 \mathrm{~cm}$, elíptico-obovado, ápice arredondado-mucronado, margem ciliada, base arredondada, face adaxial glabra, face abaxial pubescente, 2 nervuras não marcadas, membranáceo; pecíolo 0,3-0,6 cm compr., pubescente; raque $0,1 \mathrm{~cm}$; pulvínulo ausente; estipela ausente. Inflorescência terminal, espiciforme, 0,8-1,6 cm compr., pedúnculo 0,5-3 cm compr.; bráctea $0,3-0,5 \mathrm{~cm}$ compr., não cerdosa, persistente. Flor séssil, inserta na bráctea; bractéola linear, não peltada, cálice bilabiado, lacínios 5 , pétalas amarelas, estandarte obovado-orbicular, patente, guia de néctar comporto por linhas vermelhas na base; alas livres, obovadas, base auriculada; pétalas da quilha unidas, oblongo-falcadas, base auriculada; androceu monadelfo, anteras homomórficas; ovário séssil, biovulado. Fruto lomento, bissegmentado com apenas um segmento viável.

Material examinado: BRASIL. PARAíba: João Pessoa, Jardim Botânico, 16-IX-2003, fl. e fr., P.C. Gadelha Neto et al. 967 (JPB).

Stylosanthes viscosa tem como características para seu pronto reconhecimento os ramos breves e muito difusos e tricomas glandulares que confere as plantas uma certa viscosidade. Na área de estudo ocorre na área de formação de tabuleiro como supracitado. De acordo com Souza Costa (2006), esta espécie ocorre no Brasil, Cuba, Panamá, Guiana Francesa, Honduras, México e Venezuela. No Brasil apresenta ampla distribuição, ocorrendo em todos os Estados do nordeste (BFG 2015).

11. Zornia latifolia Sm., Cycl., 39: no. 4. 1819. Figuras $5 \mathrm{c}-\mathrm{d}$

Subarbusto decumbente; ramo glabro, difuso, glabro. Estípula 0,6-1,5 ×0,1 cm, não adnata ao pecíolo, estreitamente triangular, peltada. Folhas paripinadas; 2-folioladas; folíolo 2-4,2 × 0,5-1,5 cm, oposto, lanceolado a oblongo, ápice agudo-mucronado, margem inteira, base assimétrica, face adaxial glabra, face abaxial esparsamente-seríceo com glândulas, concolor, membranáceo. Pecíolo 1,3-2,8 cm compr., glabro; raque ausente; pulvínulo 0,1-0,2 cm compr., estipela ausente. Inflorescência espiciforme, laxa, 3,9-17 cm compr., pedúnculo 1-6,5 cm. Bráctea ausente, bractéola peltada, $0,5-0,8 \times 0,1-0,3 \mathrm{~cm}$, nervuras de 3-5, lanceolada, pubescente (com glândulas). Flor séssil; cálice bilabiado, lacínios 5; estandarte obovado com estrias vermelhas, alas livres obovadas; pétalas da quilha falcadas, adnatas; androceu monadelfo, anteras heteromórficas; ovário séssil, pluriovulado. Fruto lomento, 0,7-1,5 × 0,1-0,2 cm, 4-5 segmentos, planos, espinescentes, instimo ausente, ápice arredondado mucronado, margem basal crenada.

Material examinado: BRASIL. PARAíba: João Pessoa, Jardim Botânico, 8-IX-2011, fl. e fr., P.C. Gadelha 3048 (JPB); idem, 28-III-2011, fl. e fr., P.C. Gadelha 2919 (JPB); idem, 9-III-2010, fl. e fr., Gadelha Neto, P.C. et al. 2783 (JPB).

Zornia latifolia é facilmente reconhecida na Mata do Buraquinho por ser a única da tribo com folha bifoliolada e glândulas no limbo foliolar, inflorescência com bractéolas evidentes, persistentes e lomento com segmentos espinescente. Segundo Fortuna-Perez (2009) esta espécie está distribuída para Argentina, Bolívia e Brasil. No Brasil ocorre em todos os Estados da federação (BFG 2015).

\section{Agradecimentos}

Agradecemos a Rony L. Lunguinho pela confecção do mapa da área de estudo.

\section{Literatura citada}

Barbosa, M.R.V. 1996. Estudo florístico e fitossociológico da Mata do Buraquinho, remanescente de mata atlântica em João Pessoa, Paraíba. Tese de Doutorado, Universidade Estadual de Campinas, Campinas.

Brummitt, R.K. \& Powell, C.E. 1992. Authors of Plant Names. The Royal Botanic Gardens, Kew.

BFG (The Brazil Flora Group). 2015. Growing knowledge: An overview of seed plant diversity in Brazil. Rodriguesia 66: 1-29.

Cardoso, D., Queiroz, L.P. Pennington, de R.T., Lima, H.C. de, Fonty, E., Wojciechowski, M.F., Lavin, M. 2012a. Revisiting the phylogeny of papilionoid legumes: New insights from comprehensively sampled early-branching lineages. American Journal of Botany 99: 1991-2013. 
Cardoso, D., Lima, H.C. de, Rodrigues, R.S., Queiroz, L.P. de, Pennington, R.T. Lavin. M. 2012b. The realignment of Acosmium sensu stricto with the Dalbergioid clade (Leguminosae, Papilionoideae) reveals a proneness for independent evolution of radial floral symmetry among early branching papilionoid legumes. Taxon 61: 1057-1073.

Cardoso, D., Pennington, R.T., Queiroz, L.P., Boatwright, J.S., Van Wyk, B.-E, Wojciechowski, M.F., Lavin, M. 2013. Reconstructing the deep-branching relationships of the papilionoid legumes. South African Journal of Botany 89: 58-75.

Costa, L.C., Sartori, A.L.B. \& Pott, A. 2008. Estudo taxonômico de Stylosanthes (LeguminosaePapilionoideae-Dalbergieae) em Mato Grosso do Sul, Brasil. Rodriguésia 59: 547-572.

Dionísio, G.O., Barbosa, M.R. \& Lima, H.C. 2010. Leguminosas arbóreas em remanescentes florestais localizados no extremo norte da Mata Atlântica. Revista Nordestina de Biologia 19: 15-24.

Doyle, J.J., Doyle, J.L., Ballenger, J.A., Dickson, E.E., Kajita T. \& Ohashi, H. 1997. A phylogeny of the chloroplast gene rbcL in the Leguminosae: taxonomic correlations and insights into the evolution of nodulation. American Journal of Botany 84: 541-554.

Fernandes, A. 1996. O taxon Aeschynomene no Brasil. EUFC, Fortaleza.

Fidalgo, O. \& Bononi, V.L.R. 1989. Técnica de coleta, preservação e herborização de material botânico. Série Documentos, São Paulo.

Filardi, F.L.R., Lima, H.C., Klitegaard, B.B., Sartori, A.L.B. 2013. Taxonomy and nomenclature of the neotropical Machaerium hirtum complex (Leguminosae, Papilionoideae). Brittonia 65: 154-170.

Fortuna-Perez, A.P. 2009. O gênero Zornia J.F.Gmel (Leguminosae, Papilionoideae, Dalbergieae): Revisão taxômica das espécies ocorrnetes no Brasil e filogenia. Tese de Doutorado, Universidade Estadual de Campinas, Campinas.

Hughes, C.E., Lewis, G.P. Daza-Yomona, A., Reynel C. 2004. Maraniona. A new dalbergioid legume genus (Leguminosae, Papilionoideae) from Peru. Systematic Botany 29: 366-374.

IBGE (Instituto Brasileiro de Geografia e Estatística). 2012. Manual Técnico da Vegetação Brasileira. 2 ed.

Krapovickas, A. \& Gregory, W.C. 1994. Taxonomy del genero Arachis (Leguminosae). Bonplandia 8: 1-186.

Lavin, M., Pennington, R.T., Klitgaard, B., Sprent, J.I., Lima, H.C. \& Gasson, P.E. 2001. The Dalbergioid Legumes (Fabaceae): delimitation of a pantropical monophyletic clade. American Journal of Botany 88: 503-533.

Lewis, G.P. 1987. Legumes of Bahia. Royal Botanic Gardens, Kew.

Lewis, G.P. \& Schrire, B.D. 2003. Leguminosae or Fabaceae? In: B.B. Klitgaard \& A. Bruneau (eds.). Advances in Legume Systematics part 10: 1-3. Higher Level Systematics. Royal Botanic Gardens, Kew.
Lewis, G.P., Schrire, B.D., Mackinder, B.A. \& Lock, M. (eds.). 2005. Legumes of the world. The Royal Botanic Gardens, Kew.

Lima, L.C.P., Sartori, A.L.B. \& Pott, V.J. 2006. Aeschynomene L. (Leguminosae, Papilionoideae, Aeschynomeneae) no Estado de Mato Grosso do Sul, Brasil. Hoehnea 33: 419-453.

Lima, P.J. \& Heckendorff, W.D. 1985. Climatologia. In: Governo do Estado da Paraíba (eds.). Atlas geográfico do Estado da Paraíba. Universidade Federal da Paraíba, João Pessoa.

LPWG (The Legume Phylogeny Working Group). 2017. A new subfamily classification of the Leguminosae based on a taxonomically comprehensive phylogeny. Taxon 66: 44-77.

LPWG (The Legume Phylogeny Working Group). 2013. Legume phylogeny and classification in the 21st century: Progress, prospects and lessons for other species-rich clades. Taxon 62: 217-248.

Mabberley, D.J. 2008. Plant Book: A Portable Dictionary of the Vascular Plants. 3 ed. Cambridge University Press, Cambridge.

Mohlenbrock, R.H. 1957. A Revision of the Genus Stylosanthes. Annals of the Missouri Botanical Garden 44: 299-355.

Moro, M.F., Macedo, M.B., Moura-Fé, M.M., Costa, A.S.F. \& Costa, R.C. 2015. Vegetação, unidades fitoecológicas e diversidade paisagística do estado do Ceará. Rodriguésia, Rio de Janeiro 66: 717-743.

Pennington, R.T. 2003. Monograph of Andira (Leguminosae-Papilionoideae). Systematic Botancy Monographs 64: 1-143.

Polhill, R.M. 1994. Classification of the Leguminosae. In: F.A. Bisby, J. Buckingham \& J.B. Harborne (eds.). Phytochemical Dictionary of the Leguminosae. v.1. Chapman \& Hall, New York.

Polhill, R.M. 1981. Dalbergieae Bronn ex DC. In: R.M. Polhill \& P.H. Raven (eds.). Advances in legume systematics. v. 1. Royal Botanic Gardens, Kew.

Queiroz, R.T \& Loiola, M.I.B. 2009. O gênero Chamaecrista Moench (Caesalpinioideae) em áreas do entorno do Parque Estadual das Dunas de Natal, Rio Grande do Norte, Brasil. Hoehnea 36: 725-736.

Radford, A. E., W. C. Dickson, J. R. Massey \& C. R. Bel, 1974. Vascular plant systematics. Harper \& Row, New York.

Rojo, J.P. 1972. Pterocarpus (Leguminosae - Papilionaceae). Phanerogamarum Monographiae 5: 1-119.

São-Mateus, W.M.B., Cardoso, D., Jardim, J.G. \& Queiroz, L.P. 2013. Papilionoideae (Leguminosae) in the Atlantic Forest of Rio Grande do Norte, Brazil. Biota Neotropica 13: 315-362.

Sousa Costa, N.M. 2006. Revisão do gênero Stylosanthes Sw. Tese de Doutorado, Instituto Técnico de Agronomia. Lisboa.

Thiers, B. 2015. Index Herbariorum: A global directory of public herbaria and associated staff. New York Botanical Garden's Virtual Herbarium. Disponível em http:// sweetgum.nybg.org/science/ih/ (acesso em 15-IV-2015). 


\section{Lista de exsicatas examinadas}

Cariri, A.H.L. 128 (6); Gadelha, P.C. 1610 (1), 1570 (1), 3363(2), 1274 (2), 3360 (3), 1065 (4), 3668 (5), 4009 (5), 3146 (7), 3076 (8), 2782 (9), 2991(9), 967
(10), 3048 (11), 2919 (11), 2783 (11); Moura, A.C.A. 87 (4); Moura, O.T. 942 (3); Rocha, E.A. 1361 (7); Pereira, 165 (7); L.A. Pereira, M.S. 22 (1); Xavier, M. JPB 138 (2). 